\title{
Social Justice and Sociological Theory
}

\author{
Bradley Campbell ${ }^{1}$
}

Accepted: 16 August 2021 / Published online: 26 August 2021

(C) The Author(s), under exclusive licence to Springer Science+Business Media, LLC, part of Springer Nature 2021

\begin{abstract}
Sociology is the science of social life, and as such, it is different from the pursuit of social justice and other efforts to evaluate or to reform the social world. Still, the idea of social justice is intimately connected with the idea of sociology. It arises along with scientific understandings of the social world and draws from these understandings to reshape society. The problem is that in practice, social justice activists often draw from only one type of sociological theory, conflict theory, and from a particular form of conflict theory known as critical theory. In doing so, they may ignore potential problems with the theories they are drawing from, and they may overlook many possibilities for effective reform. Conflict theory orients activists toward fighting oppression, but other theoretical approaches could help societies to achieve other possible moral goals, such as promoting understanding, increasing virtue, incentivizing virtue, making virtue easier, and strengthening solidarity.
\end{abstract}

Keywords Activism $\cdot$ Social justice $\cdot$ Sociology $\cdot$ Theory

What does sociology have to do with social justice? If sociology is the science of social life, its aim is to describe and explain the social world. This is very different from social justice activism and other efforts to evaluate and reform the social world. Sociology and social justice are different enterprises, but the idea of social justice is intimately connected with the idea of sociology. It arises along with scientific understandings of the social world and draws from these understandings to reshape society. The moral goals of social justice activists cannot be derived from sociology, but to the extent, sociology is successful in describing and explaining the world; it provides an understanding of society that can enable activists and reformers to achieve their goals. They can draw from sociological theory to better understand the social world they are seeking to change.

One complication, though, is that sociology is a divided field with multiple competing perspectives, so even the most successful theories are hotly contested. Sociology can help us better understand the social world, but the lack of agreement among sociologists should lead us toward caution. If we draw too narrowly from the range of sociological theory, we may

Bradley Campbell

bcampbe3@calstatela.edu

1 Department of Sociology, California State University, Los Angeles, 5151 State University Drive, Los Angeles, CA 90032, USA ignore potential problems with the theories we are drawing from, and if we are trying to understand the social world better so that we can change it, too narrow a view may lead us to overlook many possibilities for effective reform.

Currently much social justice-oriented scholarship and activism draws from an approach called critical theory in viewing society as a system of oppression and in embracing a morality focused on liberation. Sometimes the connection is explicit. Occidental College, for example, has a Department of Critical Theory and Social Justice, and "at the heart of the program," according to the department's website, "is an interrogation of inequality and systems of power" (Occidental College 2021). Özlem Sensoy and Robin DiAngelo (2017), in their book Is Everyone Really Equal?: An Introduction to Key Concepts in Social Justice Education, are also explicit about the connection. They argue that most people fail to understand "what social justice is and what might be required to achieve it" and they see themselves as combatting a form of "society-wide social justice illiteracy" that "prevents us from moving forward to create a more equitable society" (Sensoy and DiAngelo 2017: xix). Their objective, they say, is to "provide a foundation for developing social justice literacy" (Sensoy and DiAngelo 2017: xix), and as they make clear, they believe they are providing this foundation with an analysis of social justice based on critical theory (Sensoy and DiAngelo 2017: Chapter 2). 
I agree with Sensoy and DiAngelo that there is a great deal of confusion about what social justice is and how to pursue it, but I think that by relying so heavily on critical theory, they exemplify the confusion more than they correct for it. While critical theory can certainly provide insights into the workings of society, it has not achieved the kind of consensus that would justify elevating it above other sociological approaches. And to the extent that critical theory gives us incorrect or just incomplete ideas about reality, it may lead to efforts at reform that are ineffective or even harmful. Sensoy and DiAngelo are right to think that knowledge about society can provide a foundation for social justice literacy, but our knowledge needs to be as accurate and complete as possible. Rather than focus so much on one approach, if social justice activists take seriously the full range of sociological theory, they might be able to develop more rounded conceptions of social justice that would perhaps provide a way to more accurately diagnose social problems and to more effectively deal with them.

\section{The Idea of Social Justice}

Any discussion of social justice quickly runs into the problem of how to define it. Friedrich Hayek said he had tried for 10 years to find out what social justice meant and failed. He concluded that the idea was an "empty formula, conventionally used to assert that a particular claim is justified without giving any reason" (Hayek 1979:3). Similarly, Michael Novak said social justice is most often "an instrument of ideological intimidation," that it is "a term of art whose operational meaning is, "We need a law against that"' (Novak 2000).

It is easy to see why this state of affairs would lead Hayek and others to reject the idea of social justice altogether. It is not readily apparent to me, though, that social justice is unusual in this respect. Fairness, tolerance, wisdom, love, and other moral concepts might also go undefined, and they might also be used more often as weapons in political conflicts than as tools for serious moral analysis. This does not lead most of us to reject these concepts or to stop advocating for them and pursuing them, though it might require us to think and talk about them more carefully to avoid misunderstanding. Likewise we need to be clear about what we mean by social justice.

One thing we need to be clear about is what the idea of social justice adds to our moral vocabulary. How does social justice differ from justice more broadly? One way of understanding the difference is by thinking about what was missing from older views of morality. According to David Johnston, "In the vast bulk of ancient writings that touch on questions of justice, the idea that the primary contours - the terrain - of the social world might be reshaped to conform to human design never arises" (Johnston 2011: 107). In the Iliad, he says, the status hierarchies are taken for granted, and in the Hebrew scriptures, a detailed legal code comes directly from God.
What neither the archaic and preclassical Greeks nor the ancient Hebrews imagined was "that the terrain of the social world might be re-graded to accord with a design of strictly human origins" (Johnston 2011: 108). Along with philosophical thought, the idea gradually began to emerge among the Greeks and Romans, but the older idea, that "the basic contours of the social world are determined by nature," was still a strong competitor, and with the collapse of the Roman Empire, it remained the dominant idea for many centuries (Johnson 2011: 111). As people began again to have more confidence in their ability to understand the world, though, they began to think again that the social world might be understood and even altered. Accordingly in the eighteenth century, reflections on justice began to deal with this question: "How can human beings redesign and rebuild the terrain of the social world so as to make that terrain itself just?" (Johnston 2011: 115).

Those who ask this question reject the idea that social arrangements are simply natural and inevitable. And those who ask the question are pursuing social justice. In Johnston's words, the idea of social justice is that we can develop "a set of principles from which we may work out an ideally just distribution of rights and privileges, burdens and pains, which can be deployed to assess a society's institutions as a whole and to argue for a transformation of those institutions if they are found wanting" (2011: 174). More simply, Jason Manning and I have suggested that we think of social justice as the idea "that laws, policies, and social institutions — not just individual behaviors - are part of the moral sphere" (Campbell and Manning 2018: 188). If we are concerned with social justice, we evaluate institutional arrangements in terms of whether they contribute to human flourishing, fairness, equality, or whatever else we see as morally desirable.

Understood this way, social justice is not a particular idea about how institutions should be organized; it is just the idea that the way institutions are organized is of moral concern. Understood this way, it does not make much sense to reject social justice. Few people now think of the social world as wholly natural and fixed. Political disagreements abound, but they usually involve different visions of how best to organize society rather than a disagreement about whether social arrangements can be altered at all. Social justice seems useful as a moral term, and it seems inevitable that anyone who thinks at all about the world sociologically_anyone seeking descriptions and explanations of social arrangements - would also, when thinking about the world morally, reflect on the desirability of those arrangements.

\section{Social Justice and Sociology}

There is a sense in which social justice and sociology are not connected at all. To describe and explain reality is different 
from evaluating it or changing it. What is is different from what ought to be. One way of putting this is to say that as a science, sociology is value-free. This does not mean that sociologists do not themselves have values that affect what subjects they study or that people's moral commitments do not affect their observations or interpretations. It simply means that science is not the same as morality-that science does not and cannot by itself determine what is right or wrong, good or evil, desirable or undesirable (Black 2013; Campbell 2014; Weber 1958). Science describes and explains observable reality, and descriptions and explanations are not evaluations.

That sociology is value-free is often misunderstood. To say that value judgments are not statements of fact does not mean value judgments are not important, for sociologists and for others, or that sociology is not relevant to moral debates. Sociology cannot decide between clashing values, but it can sometimes clear up matters of fact. And it can point us to what is possible - to whether and how we can act on our value commitments.

Sociology prepares the way for social justice, and in that sense, the two are intimately connected. Sociology is the science of social life, so the idea of sociology was that the old ways of thinking about the social world were inadequate. Humans had already begun to gaze upon parts of the physical world in a new way, using observation and logic to identify patterns such as the rotations of planets and the speed of falling objects. Sociologists claimed that the social world was another part of observable reality and that we could study it similarly. And if the social world could be understood like the natural world, it could be manipulated. The natural sciences provided new insights about reality, and in doing so, they enabled new technologies. Technologies manipulate the world toward human ends - faster travel, faster communication, deadlier weapons, etc. - and if the natural sciences could make new wonders possible, surely the social sciences could as well. Sociology offers the promise of social technology to enable us to live happier lives, to have more peaceful relationships, and to distribute resources more fairly. It raises the hope of social justice.

Another way social justice and sociology are intimately connected is that those who pursue social justice need sociology to help them pursue their goals. If you are going to reorganize society to reduce violence, say, or inequality, you need to know the conditions that lead to peace and violence, or equality and inequality. Just as you would not try building and flying an airplane without first knowing something about physics, it makes sense, as Axel Van den Berg puts it, "to try to understand the world a little better before rushing off to change it" (2014: 69). Social justice activists need sociology to guide them toward policies that will have the effects they intend, to ensure their attempts to reorganize society do not make things worse.
Social justice advocates generally know this, of course. As we saw with Sensoy and DiAngelo, they believe they do understand the social world and that their policy goals draw from this knowledge, but often their knowledge comes almost exclusively from a single theoretical perspective - a type of conflict theory that is increasingly prominent but has never been dominant in sociology.

\section{Social Justice and Conflict Theory}

Thomas Kuhn said that scientific revolutions were rare events in the history of science, where the dominant paradigm of a discipline - that is, the "entire constellation of beliefs, values, techniques, and so on shared by the members of a given [scientific] community" (Kuhn 1962:175) —is replaced by a new paradigm.

More relevant to understanding the situation of contemporary sociology, however, is Kuhn's discussion of what he calls pre-paradigmatic science (Kuhn 1962:17). If we alter Kuhn's definition of a paradigm slightly to include any general framework in which theories are forumulated (rather than one shared by the entire community), this period before the emergence of a dominant paradigm can more accurately be called a multi-paradigmatic period (compare Black 1995; Ritzer 1975). That is, there are usually several paradigms - several different, competing strategies of explanation. That is the current state of sociology. In sociology there is no dominant paradigm; there are a number of competing strategies of explanation. One of these is conflict theory, and it is critical theory, one form of conflict theory, that informs so much present-day social justice activism.

Conflict theory "explains human behavior as a struggle for domination" (Black 2001). Additionally, conflict theory usually assumes four things: (1) that social life involves clashes of interest, (2) that clashes of interest involve zero-sum outcomes where one side's gain is the other's loss, (3) that dominant groups gain at the expense of others, and (4) that radical change is the only way to reduce the power of dominant groups (Black 2001).

Karl Marx was the first to use this approach. For Marx the clashes of interest were between social classes, and class struggle drives historical change. In every society there has been a system of class relations, and social institutions benefit the dominant class and enable the exploitation of others. The clash between classes normally results in a new class system with a new dominant class, but Marx believed the overthrow of the current capitalist system, in which the bourgeoisie (the capitalists), who own the means of production, exploit the proletariat (the workers), who must work for wages, would put an end to class once and for all, and lead to a new kind of society. Marxists advocate revolution, and they analyze social 
relationships and institutions in capitalist societies in terms of how they benefit the bourgeoisie and exploit the proletariat.

For a Marxist studying capitalist societies, the task is not to determine whether or how much capitalists exploit workers. The approach treats exploitation as a constant to be assumed rather than as a variable to be explained. The task instead is to show how social arrangements lead to exploitation-even if those social arrangements might at first appear liberating. Thus, Marxists have argued that the idea of equality before the law actually furthers inequality. Agreements between capitalists and workers appear legitimate because they are treated as agreements between equals, even though the power dynamics mean workers are in no position to bargain. The idea of equality disguises inequality and exploitation.

Marx offered a new way of understanding societies and of understanding historical change, but his predictions have failed. The clash between capitalists and workers did not lead to the failure of capitalism and to revolution. And in societies where communist parties gained power and abolished class, doing so did not lead to a new kind of society. Government did not wither away, as Marx predicted. Instead communist reformers established totalitarian governments that were among the most intrusive and violent governments in history (Rummel 1994). Abolishing class also did not put an end to conflict and exploitation. Political elites ruled over the masses in the new societies, and they often turned on one another as they pursued power. The economic systems established also failed, leading to famine and shortages of basic goods, and eventually governments led by communist parties collapsed or made reforms.

The orthodox Marxist may be unfazed by any of this. The idea may be that capitalism will still collapse; revolution is still coming. The revolutions in Russia, China, and elsewhere were not real communist revolutions and their governments were not real Marxist governments. Marxism has not failed; real Marxism has not been tried. But another tack for those sympathetic to Marxist analysis is to accept much of Marx's framework while rejecting many of the specifics. This could mean accepting Marx's class analysis while rejecting his hope for change, but more commonly, it means accepting the conflict framework while rejecting Marx's emphasis on class alone as the source of oppression and the driver of historical change. For most of today's conflict theorists, it is not just class, but also race, gender, sexuality, religion, disability status, immigration status, and much else that give some people power over others. Otherwise the analysis is similar. The idea again is that the oppression of disadvantaged groups is a constant to be assumed rather than a variable to be explained. Just as social institutions benefit capitalists at the expense of workers, they benefit whites at the expense of persons of color, men at the expense of women, heterosexuals at the expense of gays and lesbians, the cisgendered at the expense of the transgendered, Christians at the expense of Muslims, the able-bodied at the expense of the disabled, the native-born at the expense of immigrants, etc., in an interlocking system of domination. Sometimes called critical theory or intersectional theory, this type of conflict theory follows Marxism in calling for a radical reorganization of social institutions to put an end to oppression, but it is not enough just to deal with class, as Marxists would do. And it is not enough to deal with any other single source of oppression, whether gender, race, or something else. The goal is to put an end to the entire system of oppression.

The new conflict theorists also follow Marxists in analyzing interactions and institutions - including those that might at first appear innocuous or even liberating - as sources of oppression. Laws, prisons, and wars contribute to oppression, but so do cultural practices and even ordinary conversations. One idea is that members of oppressed groups frequently experience microaggressions, small slights that make their lives unpleasant and block them from success (Sue 2010). When a person of color goes to college and sees portraits honoring mostly white men who contributed to the university or achieved success in the past, this might be a microaggression. Or it might be a microaggression when whites in conversation ask Asians where they are from. These things contribute to people feeling marginalized, and they add up.

Those who do not accept this framework may reject the idea of microaggression, particularly the idea that the intentions of the microaggressor do not matter. But what makes something a microaggression is that it furthers the oppression of those who are already disadvantaged, and it does not matter how well-intentioned someone is (Sue et al. 2007: 277-278).

Microaggression is just one of the concepts derived from critical theories that outsiders might unfamiliar and objectionable. Other new kinds of offenses include cultural appropriation (such as when members of dominant cultures the clothing styles or eat the foods associated with marginalized cultures), heteronormativity (when someone makes a statement that implies heterosexuality is normal), and white fragility (when whites are defensive over being confronted with their racism and privilege) (Ziff and Rao 1997; Warner 1991; DiAngelo 2018). Another concept that can be jarring to outsiders is the idea of white supremacy (Newkirk 2017). In more mainstream contexts white supremacy refers to things like Jim Crow laws that segregated whites and blacks and banned blacks from certain places, and white supremacists are $\mathrm{Ku}$ Klux Klansmen and others who favor such laws. But the new conflict theorists talk about mainstream institutions today as "white supremacist institutions," and they speak of those who oppose revolutionary change as "white supremacists." It is not that they believe these people are Klansmen or that the Klan or similar groups run mainstream institutions. It is that they see society's institutions as protecting the 
advantages whites have over persons of color, and this is the sense in which those institutions and those who defend them contribute to white supremacy.

By now most people are familiar with at least some of these concepts. Increasingly they are not just the argot of critical theorists in academia; concepts like microaggression, cultural appropriation, and white supremacy have made their way into workshops at universities and corporations and into the mainstream media and in public debate. Usually they are presented in the context of efforts to pursue social justice, and both the advocates and opponents of these ideas tend to see them that way, with the advocates using the term positively and the opponents using it pejoratively (such as by referring to social justice activists as social justice warriors) (Ohlheiser 2015).

The result is that social justice often becomes synonymous with a particular theoretical approach and with particular remedies. Social justice activists draw heavily from critical theory, a type of conflict theory. But it is not just conflict theorists and those who adopt the conflict framework who are concerned with social justice, and there is no reason that theoretical perspectives other than conflict theory could not form the basis for other kinds of social justice activism.

\section{Social Justice and Sociological Paradigms}

Conflict theory is not the only sociological paradigm, but what are the others? Sociologists have developed various typologies of sociological explanation. Daniel Rigney identifies eight metaphors of society that undergird different sociological perspectives: society as a living system, society as a machine, society as war, society as a legal order, society as a marketplace, society as a game, society as theater, and society as discourse (Rigney 2001). Randall Collins discusses four sociological traditions: the conflict tradition, the rational/ utilitarian tradition, the Durkheimian tradition, and the microinteractionist tradition (Collins 1994). Jonathan Turner says there are ten broad approaches to sociological theorizing: evolutionary theorizing, systems theorizing, ecological theorizing, conflict theorizing, interactionist theorizing, exchange theorizing, structuralist theorizing, cultural theorizing, and critical theorizing (Turner 2013: Chapter 9). Donald Black (2001) identifies eight sociological paradigms or strategies of explanation: conflict theory, phenomenological theory, motivational theory, neo-Darwinian theory, rational choice theory, opportunity theory, functionalist theory, and pure sociology. There are a number of other ways of classifying sociological theories, too, and they overlap substantially, but here I draw most explicitly from Black's typology, and I discuss how six of the sociological perspectives he identifies can inform ideas of social justice. ${ }^{1}$ These are some of the most commonly used perspectives in sociology, and each goes about explaining human behavior using different assumptions and employing different concepts: Conflict theory, as noted above, explains human behavior as a struggle for domination, phenomenological theory explains human behavior with the subjective experience of a person, motivational theory explains human behavior with the psychological impact of social forces, rational choice theory explains human behavior as the least costly means to a goal, opportunity theory explains human behavior with what is possible, and functionalist theory explains human behavior with its contribution to the needs of the group (Black 2001).

None of these are explanations of human behavior themselves; they are frameworks in which theorists might generate explanations. And because they offer different ways of viewing the social world, would-be reformers will understand social justice differently depending on which framework they draw from. No framework can provide answers to fundamental moral questions, but different assumptions and concepts, and different findings and explanations, will lead people toward different ways of formulating social problems and to different ways of addressing them. Just as conflict theory has inspired activists to call attention to oppression and to fight for liberation, other approaches could inspire them to pursue a variety of other possible social justice projects: to promote understanding, to increase virtue, to incentivize virtue, to make virtue easier, or to strengthen social solidarity.

\section{Promoting Understanding}

Phenomenological theory explains human behavior with the subjective experience of a person. The framework focuses on subjectivity, and phenomenologists tend to see people as creators of their own social worlds (Berger and Luckmann 1967). They may see the free will of human beings as undermining deterministic explanations, and they may be more interested in describing what it is like to experience a behavior than in explaining it (Black 2000: 357, n. 36).

The determinism of other approaches is usually what leads us to think about how we might go about altering the social world, so the anti-determinism of phenomenology means that its possible contribution to social justice is more limited or at least less apparent. Some phenomenologists do try to explain

\footnotetext{
${ }^{1}$ My use of Black's typology rather than one of the others frames the discussion, but since there is a great deal of overlap between the typologies, my argument does not depend on the typology used. However, exactly one divides up the main sociological perspectives; the different perspectives will give us different ways of thinking about social justice and different possibilities for reform.
} 
behaviors, but those explanations are less deterministic than most social science. Jack Katz (1988), for example, sees typical cases of homicide, where one person gets angry at another and kills the person on the spot, as "righteous slaughters" from the standpoint of the killers. The killers, responding to insults, adultery, and other behavior that both offends and humiliates them, see themselves as meting out justice to wrongdoers. It is the experience of moralism, anger, and humiliation that leads to the killing. Phenomenological theorists do not see these experiences as the result of socialization or some other social force; they result from internal forces - from subjective experience. How someone suddenly becomes motivated to commit crime is not explained. Katz says it is a kind of magic.

Perhaps as phenomenological theories help us to better understand how violence, discrimination, and other behaviors that we might wish to reduce are experienced by their perpetrators, we could develop ways to help would-be perpetrators develop new understandings of their situations. But if phenomenologists are correct about the mysterious and nondeterministic properties of subjectivity, we would have limited success.

Phenomenological theory is not likely to help us much in trying to change people or their behaviors, but the idea is that it still helps us understand people better. Phenomenologists may see their work as advancing social justice in that it gives dignity to the subjects. Their work treats people as having agency, and it interprets the meaning of their behaviors. Clifford Geertz, for example, provided thick descriptions of human behaviors within particular cultures. In his description of cockfighting in Bali, he argued that betting around the cockfights was a symbolic reenactment of Balinese status conflicts (Geertz 1973). The reader comes to see something that might have at first looked irrational and barbaric as purposeful and meaningful within the context it occurs. Phenomenologists may see this kind of cultural translation as promoting tolerance.

Phenomenological theory might also aid us in better understanding our political opponents. In works such as Culture Wars and Before the Shooting Begins, James Davison Hunter (1994) carefully describes the worldviews of orthodox and progressive opponents in contemporary cultural conflicts and shows that their failure to understand one another inhibits conversation and compromise. That people fail to understand one another is a concern beyond just the culture war issues. Chris Martin (2016) says that epistemic egocentrism commonly prevents understanding across political ideologies, as we evaluate others as if they shared our information and our concerns. Martin refers to a study that showed that while liberals tend to value authority less than conservatives, liberals and conservatives both thought these differences were much greater than they actually were: "liberals believed that conservatives were obsessed with authority, while conservatives believed that liberals disdained authority" (Martin 2016: 223). Their egocentrism and lack of empathy led them astray. As Martin points out, "If a liberal uses himself or herself as a reference point, thus framing morality egocentrically, he or she will assume a conservative holds moral positions that are diametrically opposite his or her own, thus rating conservatives as far more different than they actually are" (Martin 2016: 223). ${ }^{2}$

If epistemic egocentrism helps fuel the political polarization of recent years, along with the tendency of people to imagine the worst of their political adversaries and to treat them as enemies, phenomenological theory, to the extent that it accurately portrays the perspectives of its subjects, holds the promise of increased understanding and empathy.

\section{Increasing Virtue}

Motivational theory explains human behavior with the psychological impact of social forces. The idea is that institutions and interactions affect the minds of individuals and motivate them to engage in certain behaviors, whether that is altruism, violence, religion, or any other behavior. Motivational theory is as individualistic as phenomenological theory, in that behavior stems from motivations, but motivational theory is more deterministic: The motivations that affect behavior are social products; society shapes the individual (Black 2000: 357, n. 36). Motivational theory is thus compatible with one kind of reformist project: that of shaping moral character so that people engage in more virtue and in less vice.

Black (2001) points out that motivational theories come in four forms. Learning theories explain motivations as the result of socialization, bonding theories explain them with the presence or absence of attachments, compliance theories explain them with social pressure, and strain theories explain them with psychological discomfort. Whatever the nature of the explanatory mechanisms, the idea is that individuals are shaped by their social environments. The task for reformers drawing from this approach, then, would be to discover how they might alter social environments to reduce motivations toward behavior they see as undesirable and increase motivations toward behaviors they see as desirable. This could mean educational reform, changes in foster care, and other efforts to better socialize children. It could mean communitarian policies that seek to promote the kinds of social ties that encourage prosocial behavior. It could even mean more fundamental institutional change, as advocated by Steven Messner and Richard Rosenfeld (2012) in Crime and the American Dream. Messner and Rosenfeld argue that

\footnotetext{
${ }^{2}$ Consider also how last year's debates over closures due to COVID-19 led to mutual recrimination and misrepresentations of each side's position, with lockdown supporters accusing lockdown opponents of "human sacrifice," and the opponents accusing the supporters of "fascism" (Paresky and Campbell 2020).
} 
the USA has high rates of violent crime compared to other advanced industrial democracies in part because of an institutional imbalance where the economy is valued more than institutions such as the polity, the family, and education. This leads to a highly competitive society in which crime flourishes, but altering the institutional imbalance, such as by strengthening social welfare programs, would reduce crime.

Those who draw from motivational theory in pursuit of social justice might focus on institutions, then, but it is in terms of how those institutions impact individuals. Accordingly, this tends to be the approach of liberal reformers rather than revolutionaries. Usually such reformers are optimistic about the ability of the insights of social science to help reduce suffering and injustice and optimistic that this is possible by modifying current social arrangements rather than destroying them.

\section{Incentivizing Virtue}

Rational choice theory explains human behavior as the least costly means to a goal. It focuses on the interests of individuals, but it is unlike motivational theory in that the characteristics of individuals are usually treated as a constant rather than a variable. Rational choice theorists may assume that individuals are pursuing their own happiness, for example, and what explains variation in their behavior is not variation in their goals; it is variation in their interests. A variable that might help them achieve their goals on one occasion might not on another.

Rational choice theory is the dominant paradigm in economics, and it is associated with free market perspectives. Economists and rational choice sociologists, though, have applied this type of thinking outside the marketplace - to religion, to romantic relationships, and to many other areas where people might at first seem to be behaving irrationally. Rational choice theorists might recommend a variety of policies across the political spectrum, but whatever their recommendations, the central task for those drawing from rational choice theory to pursue social justice is to determine how social arrangements might best incentivize what they see as good behavior and make costly what they see as bad behavior. The goals are more modest — change behavior, not character - since there is no assumption that virtue and vice stem from character.

Enlightenment reformers of the eighteenth century used this approach to argue for changes in the legal systems of the time. The deterrence theory of crime and punishment proposes that people are less likely to commit crimes, the more certain, swift, and severe the punishment is. The idea is that punishment makes crime costly — not in the interests of the would-be criminal. To do this, punishment just needs to outweigh the benefits of the crime, so the reformers argued for reducing the harsh penalties in effect at the time. The certainty of punishment is much more important, and this often puts contemporary deterrence theorists at odds with both liberals and conservatives, since they favor frequent use of the justice system, which liberals might be concerned about, but they oppose the harsh penalties conservatives might favor.

Other applications of rational choice theory have similarly led to policy proposals that challenge conventional thinking. Olson (1990) addressed the different individual interests related to private goods and public goods. With private goods, it is clearly in people's interest to protect and take care of whatever they own. But public goods are owned collectively - they are available to everyone. It is therefore not in anyone's individual interest to contribute to protecting public goods, even though they derive a benefit from them. This is known as the free-rider problem: Everyone would be better off cooperating, but it is in everyone's individual interest not to do so. One thing this means is that larger groups will not naturally pursue their group interests, and this is one reason Marx was wrong to think the working class would perceive its interests and then revolt.

There is always the danger that public goods simply will not be provided or protected, but just as incentives or punishments might alter the likelihood of someone committing crime, inducements and coercion can ensure that public goods get provided. Rational choice theory is often used to defend free markets, then, but Olson's analysis helps us understand why the free market will fail when public goods are involved. His analysis shows why labor unions are likely to fail if they are completely voluntary, for example, and why government involvement might be needed to protect the environment.

Another rational choice theorist, James Buchanan (2000), showed why politics often fail. Individuals involved in politics - voters, politicians, and others - act according to their own interests. Politics is a competitive marketplace. Politicians compete for votes, for example, and they do so by spending money on things voters like. It is not in the self-interest of voters to pay taxes, though, so politicians end up borrowing and spending, rather than reducing spending or raising taxes. This is rational for everyone involved but only in the short run.

For those pursuing policy changes, these kinds of theories could serve as essential starting points or at least as correctives enabling them to better pursue their goals. Social institutions are not changed in a vacuum; individuals are involved, and one runs the risk of not anticipating the effect one's policies will have, or how they will be dealt with in the political realm, without taking into account the immediate and individual interests of all those involved.

\section{Making Virtue Easier}

Opportunity theory explains human behavior with what is possible. Opportunity theorists assume certain motivations and goals, and the idea is that certain social conditions prevent or enable people from achieving those goals. In criminology 
this might mean assuming the motivation to commit various crimes, but explaining variation in crime with factors make the crimes easier (e.g., Cohen and Felson 1979). The layout of a store could encourage shoplifting by placing valuable and small objects where they are easy to get, or the layout of a neighborhood could encourage burglary by providing routes where burglars could travel on foot without a high likelihood of being seen.

Just as people may have the motivation to commit crime but not the opportunity, they might desire friendships across cultural boundaries without the ability to form any. Peter Blau (1980) pointed out that when the numbers of different population groups differ, the numbers of friendships possible across those groups is limited. In areas where whites greatly outnumber racial minorities, for instance, most whitesregardless of their preferences - would not have the opportunity for an interracial friendship.

Whether one is seeking to reduce crime or increase racial integration, opportunity theory points to the need to consider what is possible under certain conditions. The task for those using the approach to pursue social justice is to find ways to alter the opportunity structure. The idea would not be to change hearts and minds, or even to incentivize virtue, but simply to make virtue possible more often, and vice impossible more often. And while the use of opportunity theory in this manner might be limited, it is likely to be effective. It is also an area where it is easy to see the distinction between ordinary justice and social justice. If two neighborhoods have different rates of crime not because of the motivations of potential criminals but because the design of one prevents many opportunities for crime, people might seek to alter the design of the high-crime neighborhood or at the very least to design new neighborhoods differently. The design of neighborhoods might become a moral issue - a social justice issue. But it may not have been bad intentions or bad behavior that led to the different designs in the first place. No one would have behaved unjustly when they built the neighborhoods, and individual criminals would still be blamed for their crimes. It is simply that better information now makes it possible to make social changes that reduce harm, and with that knowledge, doing so might become a moral imperative.

\section{Strengthening Solidarity}

Functionalist theory explains human behavior with its contribution to the needs of the group. ${ }^{3}$ Functionalist theorists see society as akin to an organism, with distinct and necessary

\footnotetext{
$\overline{3}$ Black (2001) actually calls this strategy "systems theory," and he refers to systems theory and the approach he calls neo-Darwinian theory together as "functionalism," but I follow many others here in using functionalism to refer to systems theory alone.
}

parts that contribute to the functioning of the whole society, just like the heart, lungs, skin, and central nervous system of the human organism contribute to the needs of the whole body. Talcott Parsons used this strategy when he identified four basic problems all societies needed to solve-adaptation, goal attainment, integration, and latent pattern managementand pointed to the way social institutions such as the economy, the political order, law, religion, education, and the family solve them (Turner 2013: 352-354).

If motivational theory tends to be associated with liberal politics, and conflict theory with radical politics, functionalist theory is most associated with conservative politics. It is true that many functionalists have been liberals and that many functionalist analyses — such as Émile Durkheim's argument that crime strengthens social solidarity or Kingsley Davis's (1937) argument that prostitution strengthens the familyare contrarian takes that would offend many conservatives. Still, since the gist is that social institutions provide stability and meet social needs, functionalists tend to point to what most people would see as the positive and prosocial aspects of social institutions rather than their negative and oppressive aspects. Conservatives also tend to be concerned with social order and suspicious of radical change and the chaos they fear it will produce, and functionalist analyses often point to the conditions leading to social solidarity, social stability, and harmonious relationships.

Liberals and radicals may question whether conservatives concerned with preserving or strengthening social institutions for the common good are pursuing social justice at all, but many conservatives accept that society is to some extent malleable and that the design of social institutions should be of moral concern. To the extent that they resist change, they may simply be more cautious than others because of the harm and injustice they believe the weakening of social institutions will cause. In their efforts to protect institutions, they are trying to strengthen what psychologist Jonathan Haidt calls moral capital_ " "the resources that sustain a moral community." These include "interlocking sets of values, virtues, norms, practices, identities, institutions, and technologies that mesh well with evolved psychological mechanisms and thereby enable the community to suppress or regulate selfishness and make cooperation possible" (Haidt 2012: 292). Conservatives tend to value moral capital over diversity, equality, and other things valued more by liberals and radicals. Perhaps they are wrong about the tradeoffs, and perhaps the functionalist view of society is limited or distorted. But functionalist analysis might even be able to help those on the left more effectively change society toward the ends they value. However, you alter social institutions, when you are finished you still face the problem of preserving the new social order you have created. As Haidt says, "if you are trying to change an organization or a society and you do not consider the 
effects of your changes on moral capital, you're asking for trouble" (2012: 294).

\section{Conclusion}

Whether or not the multi-paradigmatic nature of sociology is healthy is a matter of debate. If we follow Kuhn in seeing the dominance of a paradigm as a sign of a mature science, then it is not. But whether it is healthy or not, and whatever the reasons for it, it is the current state of sociology, and it does little good to pretend otherwise. We cannot just declare a dominant paradigm - that has to be established through evidence and consensus and currently that does not exist. It is thus odd that current social justice activism, even in its institutional forms at universities and corporations, so often draws from only one of the many theoretical approaches in sociology, as if conflict theory, and this particular version of it, a marginal approach in the field and only one of many, had become dominant and its claims uncontested.

Activists and their allies who take this approach run the risk of making unwarranted assumptions and even treating claims as fact that have little empirical support. The idea of microaggression, for example, first developed by critical race theorists and later taken up by critical theorists more broadly, has become institutionalized now, with microaggression reporting systems at many universities and microaggression awareness workshops at many universities and corporations. When Scott Lilienfeld (2017) investigated the claims of microaggression theorists, though, he found little support for them. This means that a great deal of political and institutional energy has been spent promoting ideas that might be incorrect and which might even harm those they are intended to help (al-Gharbi 2020; Lukianoff and Haidt 2015, 2018). And this is likely true of many other ideas formulated using the conflict perspective. Of the various sociological paradigms, conflict theory, and particularly the version often known as critical theory, is the most overtly political, and its adherents are often hostile to science or at least to the idea that sociology can or should be scientific. Sometimes conflict theory acts more as a political ideology than a sociological paradigm, and while it provides a distinctive model of society and many new concepts for thinking about social relations, those working within this perspective have mostly failed to produce general and testable propositions about social life. ${ }^{4}$ When they do make testable claims, as with Marx's predictions about the fall of capitalism and the end of class and with the microaggression claims that Lilienfeld tested, they often turn

\footnotetext{
4 There are important exceptions, though. Theorists such as Ralf Dahrendorf (1956) and Randall Collins (1975) have developed more scientific conflict theories that could also be used to develop strategies for social justice that would differ from those of critical theorists.
}

out to have little support. That the claims of conflict theorists are often untestable or unsupported has led even many sociologists who support the political aims of conflict theory to reject it at as a sociological approach or at least to deal with it cautiously.

Meanwhile the field of sociology is saturated, possibly oversaturated, with perspectives and explanations of social reality. These various paradigms can each provide ways of thinking about and pursuing social justice that differ from those of most social justice activists. Fighting systematic oppression is but one possible aim of social justice, and those with broader moral concerns and a broader awareness of strategies of effecting change might also wish to change the world by promoting understanding, increasing virtue, incentivizing virtue, making virtue easier, or strengthening solidarity, and they might draw from a variety of perspectives other than conflict theory to aid them in doing so. Currently, social justice activists who draw mainly from a tiny sliver of sociology run the risk that their efforts will be based on a distorted understanding of reality. While it would be irresponsible to try to reshape society while ignoring sociology entirely, it is also irresponsible to do so while ignoring most of the field. Dealing with a fragmented, multi-paradigmatic field may be hard, and it may be unsatisfying to find that with much of our knowledge about ourselves and our societies contested, there are few easy answers to our problems. But if we are serious about improving the world, we need to be willing to face social reality as we find it. This is the true foundation for developing social justice literacy.

\section{References}

Al-Gharbi, Musa. 2020. "Who Gets to Define What's Racist?" Contexts, May 15. https://contexts.org/blog/who-gets-to-define-whats-racist/

Berger, Peter L. and Thomas Luckmann. 1967. The Social Construction of Reality: A Treatise in the Sociology of Knowledge. Garden City: Anchor Books.

Black, Donald. 1995. "The Epistemology of Pure Sociology." Law \& Social Inquiry 20: 829-870.

Black, Donald. 2000. "Dreams of Pure Sociology." Sociological Theory 18(3): 343-367.

Black, Donald. 2001. Lectures in Contemporary Sociological Theory (SOC 506). University of Virginia.

Black, Donald. 2013. "On the Almost Inconceivable Misunderstandings Concerning the Subject of Value-Free Sociology." British Journal of Sociology 64(4): 763-780.

Blau, Peter. 1980. "A Fable about Social Structure." Social Forces 58: 777-788.

Buchanan, James M. 2000. Politics as Public Choice. Liberty Fund.

Campbell, Bradley, 2014. "Anti-Minotaur: The Myth of a Sociological Morality." Society 51(5): 443-451.

Campbell, Bradley and Jason Manning. 2018. The Rise of Victimhood Culture: Microaggressions, Safe Spaces, and the New Culture Wars. New York: Palgrave MacMillan. 
Cohen, Lawrence E. and Marcus Felson. 1979. "Social Change and Crime Rate Trends: A Routine Activity Approach." American Sociological Review 44: 588-608.

Collins, Randall. 1975. Conflict Sociology: Toward an Explanatory Sociology. New York: Academic Press.

Collins, Randall. 1994. Four Sociological Traditions. New York: Oxford University Press.

Dahrendorf, Ralf. 1956. “Toward a Theory of Social Conflict.” Journal of Conflict Resolution 2: 170-183.

Davis, Kingsley. 1937. "The Sociology of Prostitution." American Sociological Review 2(5): 744-755.

Van den Berg, Axel. 2014. "Public Sociology, Professional Society, and Democracy." In The Public Sociology Debate: Ethics and Engagement, edited by Arianne Hannemaayer and Christopher J. Schneider, 53-73. Vancouver: UBC Press.

DiAngelo, Robin. 2018. White Fragility: Why It's So Hard for White People to Talk about Racism. " Boston: Beacon Press.

Geertz, Clifford. 1973. The Interpretation of Cultures. New York: Basic Books.

Haidt, Jonathan. 2012. The Righteous Mind: Why Good People Are Divided by Politics and Religion. New York: Pantheon Books.

Hayek, Friedrich. 1979. Social Justice, Socialism, and Democracy: Three Austrian Lectures. Centre for Independent Studies. https://www.cis. org.au/app/uploads/2015/07/op2.pdf

Hunter, James Davison. 1991. Culture Wars: The Struggle to Define America. New York: Basic Books.

Hunter, James Davison. 1994. Before the Shooting Begins: Searching for Democracy in America's Culture Wars. New York: The Free Press.

Johnston, David. 2011. A Brief History of Justice. Malden, Massachusetts: Wiley-Blackwell.

Katz, Jack. 1988. Seductions of Crime: Moral and Sensual Attractions of Doing Evil. New York: Basic Books.

Kuhn, Thomas S. 1962. The Structure of Scientific Revolutions. Chicago: University of Chicago Press.

Lilienfeld, Scott. 2017. "Microaggressions: Strong Claims, Inadequate Evidence.” Perspectives on Psychological Science 12(1): 138-169.

Lukianoff, Greg and Jonathan Haidt. 2015. "The Coddling of the American Mind." The Atlantic, September. https://www. theatlantic.com/magazine/archive/2015/09/the-coddling-of-theamerican-mind/399356/

Lukianoff, Greg and Jonathan Haidt. 2018. The Coddling of the American Mind: How Good Intentions and Bad Ideas Are Setting Up a Generation for Failure. New York: Penguin Press.

Martin, Chris C. 2016. "How Ideology Has Hindered Sociological Insight." The American Sociologist 47: 115-130.

Messner, Steven and Richard Rosenfeld. 2012. Crime and the American Dream, Fifth Edition. Belmont, California: Wadsworth.

Newkirk, Vann R. II. 2017. "The Language of White Supremacy." Atlantic, October 6. https://www.theatlantic.com/politics/archive/ 2017/10/the-language-of-white-supremacy/542148/

Novak, Michael. 2000. "Defining Social Justice." First Things, December. https://www.firstthings.com/article/2000/12/definingsocial-justice
Occidental College. 2021. "Critical Theory and Social Justice." https:// www.oxy.edu/academics/areas-study/critical-theory-social-justice

Ohlheiser, Abby. 2015. "Why 'Social Justice Warrior,' a Gamergate Insult, Is Now a Dictionary Entry." Washington Post, October 7. https:/www.washingtonpost.com/news/the-intersect/wp/2015/10/ 07/why-social-justice-warrior-a-gamergate-insult-is-now-adictionary-entry/

Olson, Mancur Jr (1990) The Logic of Collective Action: Public Goods and the Theory of Groups. Cambridge: Harvard University Press.

Paresky, Pamela and Bradley Campbell. 2020. "Safetyism Isn't the Problem." New York Times, June 1. https://www.nytimes.com/ 2020/06/01/opinion/safetyism-coronavirus-reopening.html.

Rigney, Daniel. 2001. The Metaphorical Society: An Invitation to Social Theory. Lanham, Maryland: Rowman and Littlefield.

Ritzer, George. 1975. "Sociology: A Multi-Paradigm Science." The American Sociologist 10: 156-167.

Rummel, R. J. 1994. Death by Government. New Brunswick, New Jersey: Transaction Publishers.

Said, Edward. 1978. Orientalism: Western Conceptions of the Orient. London: Penguin Press.

Sensoy, Özlem and Robin DiAngelo. 2017. Everyone Equal: An Introduction to Key Concepts in Social Justice Education, Second Edition. New York: Teachers College Press.

Sue, Derald Wing. 2010. Microaggressions in Everyday Life: Race, Gender, and Sexual Orientation. Hoboken, New Jersey: Wiley and Sons.

Sue, Derald Wing, Christina M. Capodilupo, Gina C. Torino, Jennifer M. Bucceri, Aisha M. B. Holder, Kevin L. Nadal, and Marta Esquilin. 2007. "Racial Microaggressions in Everyday Life: Implications for Clinical Practice." American Psychologist 62(4): 271-286.

Turner, Jonathan. 2013. Theoretical Sociology: 1830 to the Present. Los Angeles: Sage.

Warner, Michael. 1991. "Introduction: Fear of a Queer Planet." Social Text 29: 3-17.

Weber, Max. 1958. "Science as a Vocation.” Pp. 129-156 in From Max Weber: Essays in Sociology, edited by H. H. Gerth and C. Wright Mills. New York: Oxford University Press.

Ziff, Bruce and Pratima V. Rao. 1997. Borrowed Power: Essays on Cultural Appropriation. New Brunswick, New Jersey: Rutgers University Press.

Publisher's Note Springer Nature remains neutral with regard to jurisdictional claims in published maps and institutional affiliations.

Bradley Campbell is professor of sociology at California State University, Los Angeles. He is the author of The Geometry of Genocide: A Study in Pure Sociology and coauthor of The Rise of Victimhood Culture: Microaggressions, Safe Spaces, and the New Culture Wars. 